\title{
GEOMORFOLOGIA DA BACIA HIDROGRÁFICA DO CÓRREGO SALOBRA, MUNICÍPIO DE PORTO ESTRELA - MATO GROSSO
}

\author{
Willian Cosme da Silveira de Paula ${ }^{(a)}$, Ione Cristina de Souza (b) Celia Alves de Souza ${ }^{(b)}$, \\ (a) Departamento de Geografia (UNEMAT) - e-mail: willtmt15@gmail.com \\ (b) Rede Pública Estadual - e-mail: ionexenefonte@ bol.com.br \\ (c) Professora Departamento de Geografia (UNEMAT) - e-mail: celiaalvesgeo@globo.com
}

\section{Eixo: SISTEMAS GEOMORFOLÓGICOS: ESTRUTURA, DINÂMICAS E PROCESSOS}

\begin{abstract}
Resumo
A pesquisa teve como objetivo verificar a geomorfologia da bacia hidrográfica do córrego Salobra, MT. Os procedimentos metodológicos se deram por meio de revisão bibliográfica, trabalhos de gabinete e de campo. A área da bacia foi delimitada de acordo com as cartas topográficas do Ministério do Exército (1975) em escalas de 1:100.000, folhas Serra da Palmeira e Barra do Bugres SD-21-Y-D-VI e SD-21-Y-D-III. O mapa de geomorfologia, foi elaborado a partir dos mapas temáticos do projeto RADAMBRASIL. Sua arte final foi realizada no programa ArcGis 10.1. Os resultados mostraram que a bacia possui três unidades geomorfológica: Província Serrana, Depressão do Alto Paraguai e Planície do rio Paraguai. No alto curso da bacia, o canal encontra-se encaixado apresentando vários segmentos retilíneos. No médio curso se apresenta meandro divagante até a foz.
\end{abstract}

Palavras-chave: Província Serrana; Depressão do Alto Paraguai; Planície do rio Paraguai.

\section{Introdução}

Cunha e Guerra (2008) apresentam bacia hidrográfica como uma unidade geomorfológica importante, pelo fato de nela interagirem os fatores físicos, biológicos, econômicos e sociais.

O conhecimento dos aspectos ambientais (geologia, geomorfologia, tipos de solos e cobertura vegetal) da bacia hidrográfica é importante para definir os padrões de drenagem, o grau de armazenamento e a própria dinâmica do canal (SOUZA, 2008).

O estudo da geomorfologia permite identificar as principais formas e relevo de diferentes tamanhos, sua formação e inter-relação com os demais componentes da natureza, e, portanto, são dinâmicos (ROSS, 2011).

A geomorfologia possui o espaço próprio na análise ambiental, pois auxilia no entendimento e compreensão da paisagem, bem como das relações entre homem e natureza e sociedade, criando novas visões para a pesquisa e enfoques ambientais. (GUERRA e MARÇAL, 2010).

Os autores acrescentam que, a ciência geomorfológica procura compreender as formas de relevo em diferentes escalas espaciais e temporais, suas características morfológicas, materiais componentes e 
dinâmicas evolutivas, explicando não só a sua gênese, mas também como evoluem no tempo e no espaço, levando em conta os processos geomorfológicos que atuam e modelam o relevo terrestre.

A pesquisa teve como objetivo verificar a geomorfologia da bacia hidrográfica do córrego Salobra, afluente da margem esquerda do rio Paraguai, localizada no município de Porto Estrela, região Sudoeste de Mato Grosso.

\section{Material e Métodos}

\section{1. Área de Estudo}

A bacia hidrográfica do córrego Salobra está localizada no município de Porto Estrela, região Sudoeste do Estado de Mato Grosso, possui aproximadamente $779,18 \mathrm{~km}^{2}$, o canal principal possui

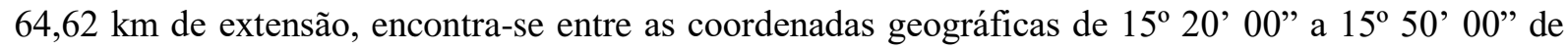
latitude Sul e $57^{\circ} 02^{\prime} 00^{\prime \prime}$ a $57^{\circ} 20^{\prime} 00^{\prime \prime}$ longitude Oeste, suas principais nascentes estão situadas nas encostas dos vales da Província Serrana, percorre um trecho de depressão e deságua na margem esquerda do rio Paraguai (Figura 01).

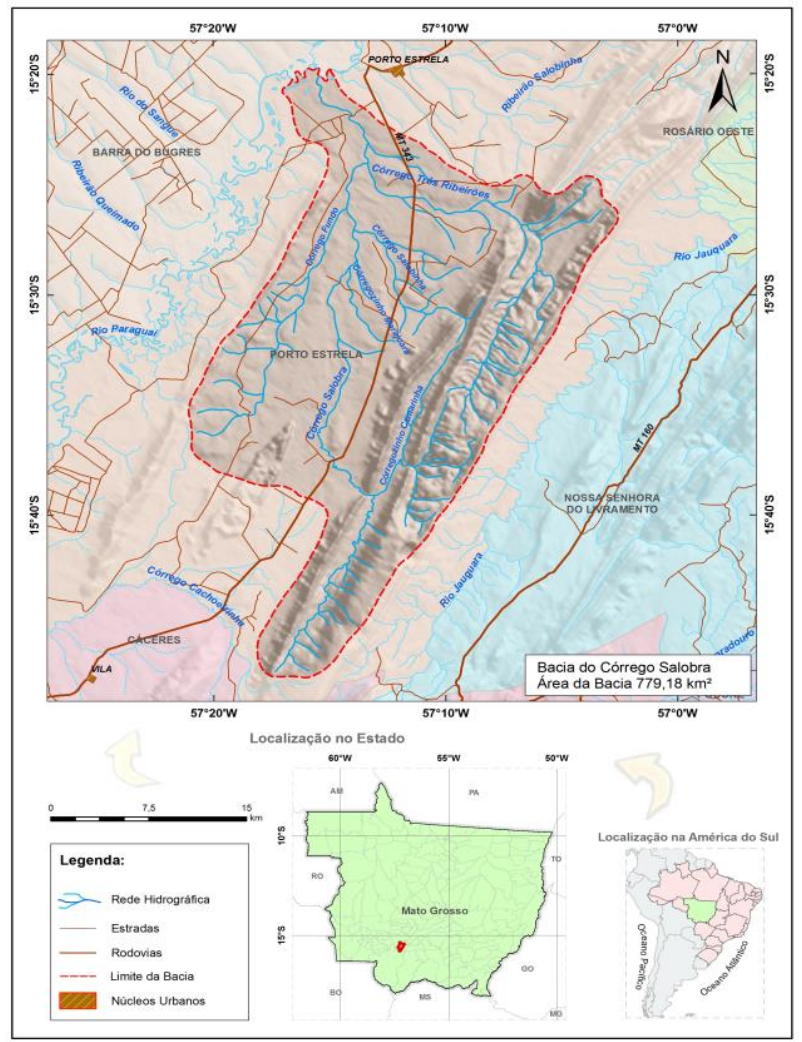

Figura 01 - Mapa de localização da bacia hidrográfica do córrego Salobra. Mapa Adaptado: Diretoria de Serviços Geográficos do Exercito Brasileiro (1975), atualizadas por meio de imagens de satélite LANDSAT / 5 . 
Realizou-se leitura de obras pertinentes à pesquisa, levantamento de informações sobre a bacia, compilação de dados e confecção do mapa geomorfológico. Para o levantamento geomorfológico utilizou-se dados secundários do relatório (RADAMBRASIL, 1982).

\section{Resultados e Discussão}

\subsection{Geomorfologia}

A bacia hidrográfica do córrego Salobra, geomorfologicamente possui três unidades importantes, os estudos elaborados pelo projeto (RADAMBRASIL, 1982), possibilitaram classificar a bacia em compartimentos geomorfológicos distintos: a) Província Serrana, b) Depressão do Alto Paraguai (Formas de Dissecação) e c) Planície do Rio Paraguai (Formas de Acumulação) (Figura 2). 


\section{OS DESAFIOS DA GEOGRAFIA FÍSICA NA FRONTEIRA DO CONHECIMENTO \\ Instituto de Geociências - Unicamp \\ Campinas - SP \\ 28 de Junho à 02 de Julho de 2017}

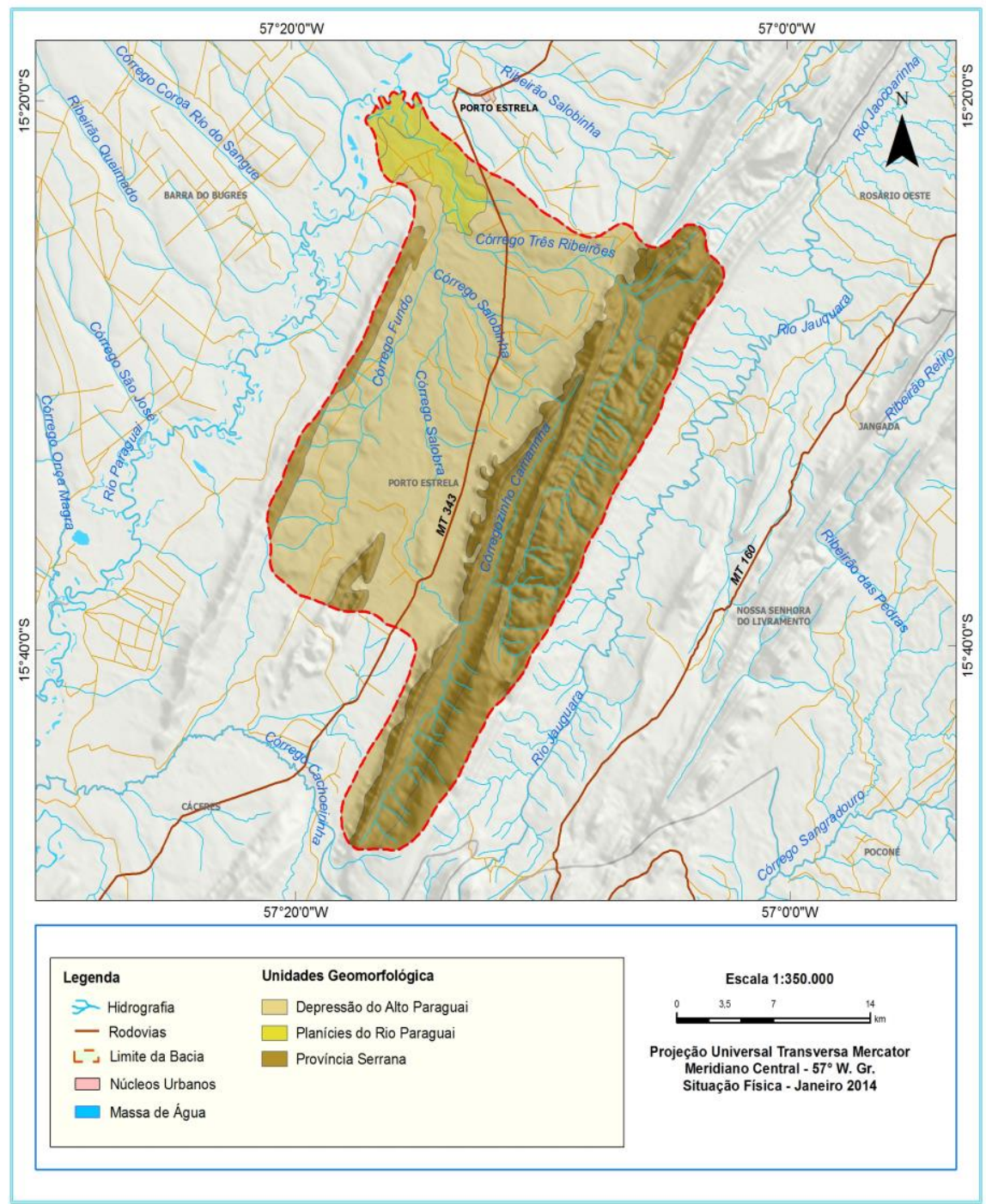

Figura 2 -Mapa geomorfológico da bacia hidrográfica do córrego Salobra em Porto Estrela, MT. Mapa Adaptado: RADAMBRASIL (1//982), atualizado por meio de imagens de satélite LANDSAT / 5.

\subsection{Província Serrana}

O alto curso da bacia hidrográfica do córrego Salobra apresenta variações nos aspectos geomorfológicos, uma vez que se encontra inserido em relevo, movimentado da Província Serrana, abrange $325,17 \mathrm{~km}^{2}$, corresponde a $41,73 \%$ da bacia. Caracterizado por um conjunto de vales e serras paralelas, sinclinais e anticlinais com grande simetria, constituídas por dobramentos e falhamentos.

No alto curso, as serras mais expressivas são: serra do Sabão, Bocaina, Camarinha, Três Ribeirões e serra Grande. Esse conjunto de serras paralelas dá uma característica própria ao alto curso, como morfologia do canal, e padrão de drenagem. $\mathrm{O}$ alto curso da bacia do córrego Salobra é representado pelos dobramentos que constituem a Província Serrana (Figura 03). 

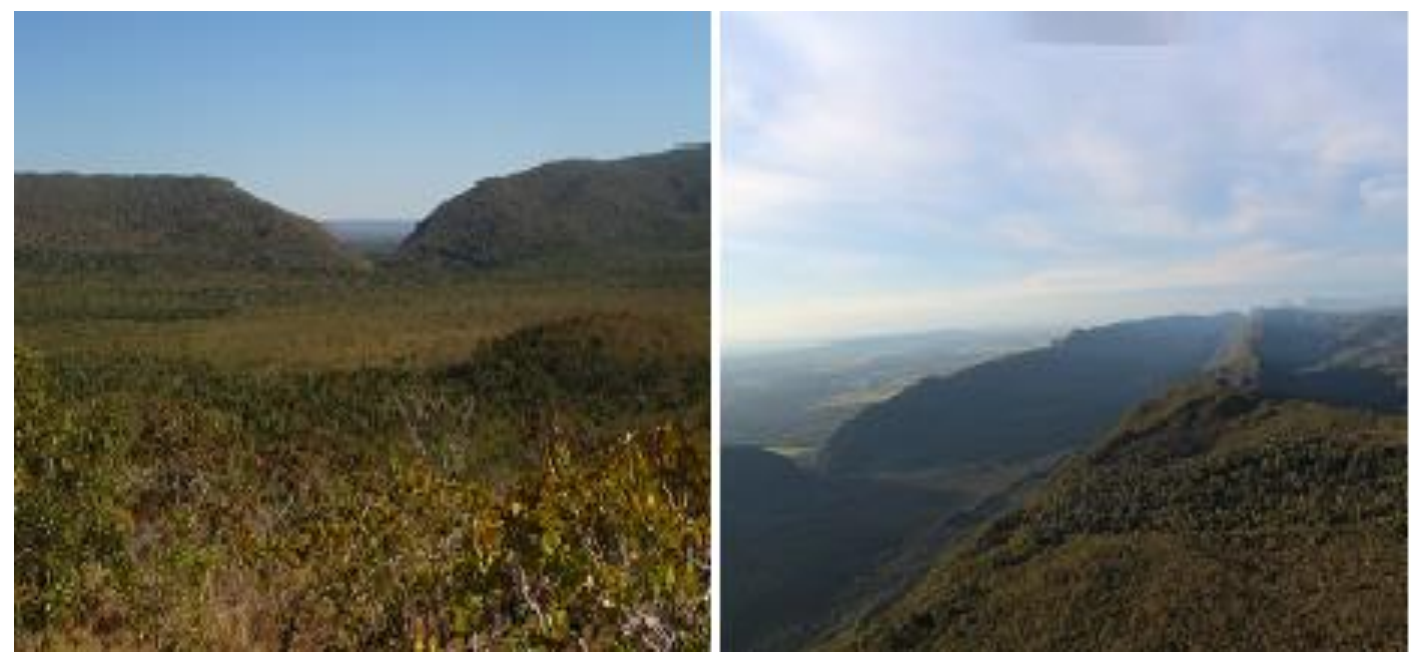

Figura 03- Serras inseridas na bacia do córrego Salobra, Porto Estrela - MT.

Os estudos realizados por Ross (1987) contribuíram para classificar o relevo da Província Serrana (Superfície Dissecada), como um conjunto de anticlinais e sinclinais formando um alinhamento de serras grosseiramente paralelas entre si, com plano de concavidade voltado para o sudoeste, caracterizado por forte presença de dobras e secundariamente falhas, onde o processo erosivo atuou em diferentes fases ao longo do Cenozoico, e até mesmo no Mesozoico.

Ribeiro Filho; Luz; Abreu Filho (1975) descreveram a província Serrana como um sistema contínuo de serras paralelas, configuradas por dobramentos e falhamentos das camadas sedimentares do Grupo Alto Paraguai.

Almeida (1965) identificou a Província Serrana como sendo o mais importante sistema de dobramentos, possivelmente do paleozóico inferior, que constitui divisor de águas das bacias CuiabáParaguai. Classificou como um sistema de serras paralelas separadas entre si por longos vales em sinclinais, representadas pelas (Figuras 4 e 5). 


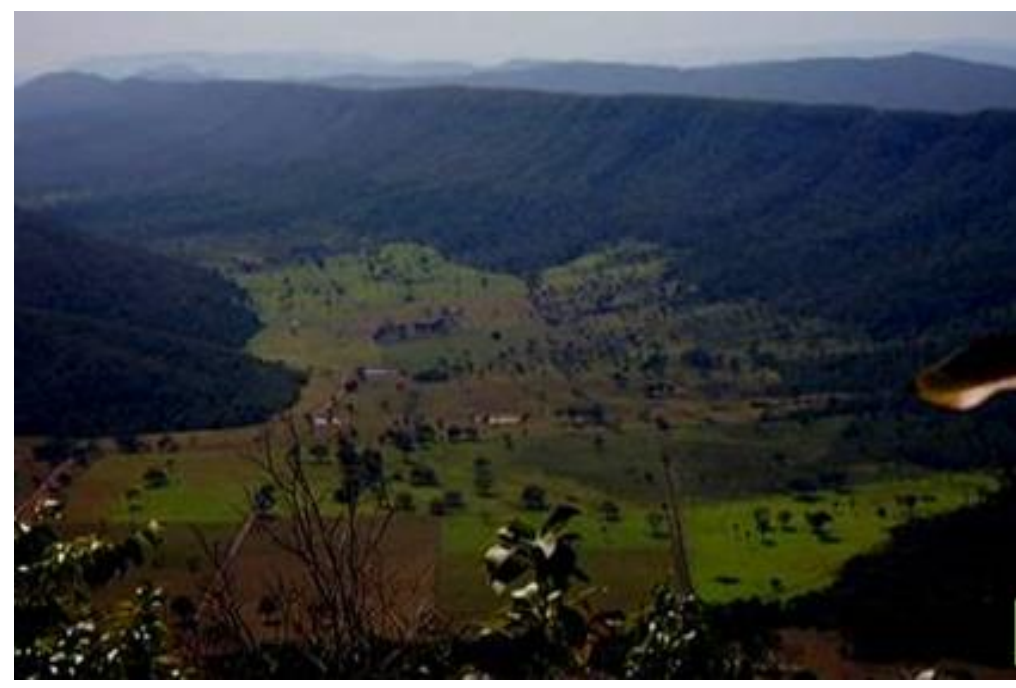

Figura 4 - Vista panorâmica de vale, no complexo da Província Serrana.

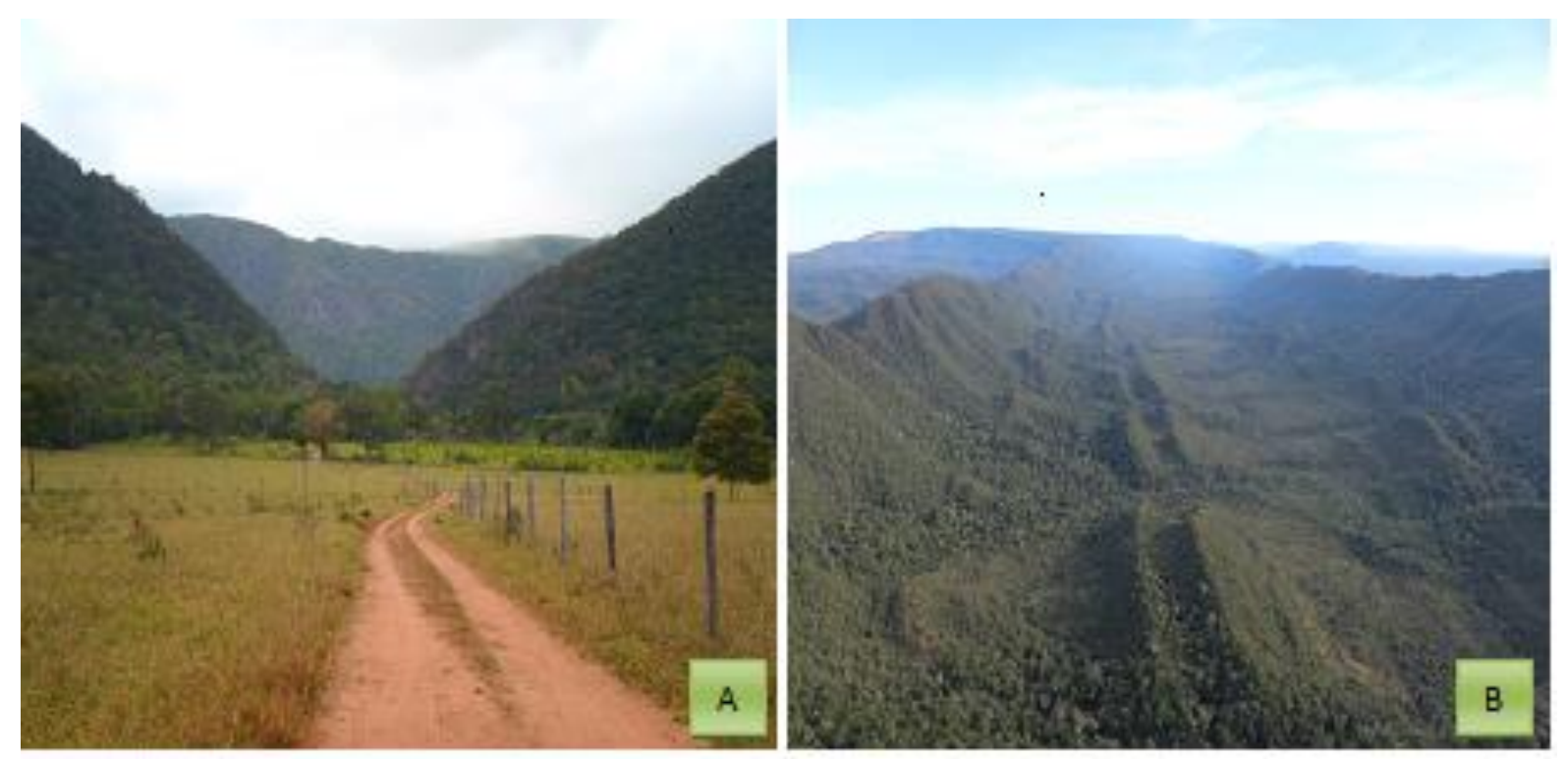

Figura 5 - (A) Vale dissecado da serra do Sabão, (B) Conjunto de serras da Província Serrana.

O relevo atual é resultado das fases erosivas que atuaram na estrutura dobrada, de diferentes formações litológicas. Apresenta-se com variadas formas, ocorrendo estrutura em anticlinais com dorsos preservados, erodidos, vales de sinclinais preservados, sinclinais alçados, escarpas estruturais geradas por falhas, depressões embutidas e arrasadas por erosão. Pode-se destacar a relação entre cristas ou relevo alto (presença de rochas areníticas) e a ocorrência dos calcários no interior dos anticlinais erodidos ou na parte externa das bordas sinclinais alçadas, podendo-se observar uma associação do relevo invertido e formas concordantes com a disposição estrutural. 
A rede de drenagem é influenciada pelo controle estrutural da Província Serrana, seu curso está encaixado entre os vales formados por sinclinais e anticlinais, constituindo uma rede de drenagem mais retilínea, devido ao conjunto de serras nessa unidade.

No alto curso da bacia, o escoamento pluvial ocorre de forma rápida devido ao aspecto do relevo. Segundo Santos (2012), o escoamento rápido se dá por meio das vertentes que estão nos vales da Província Serrana, não havendo tempo suficiente para infiltração. O autor cita Alonso (2007), que descreve que as encostas das serras que possuem um rampeamento acentuado, o fluxo pluvial desce de forma turbulenta reduzindo o volume de água que abastece o lençol freático.

Desta forma, no alto curso do córrego Salobra em períodos de chuvas ocorre o aumento substancial no volume do fluxo de água, porém com rápido escoamento devido às características locais e declividade do terreno influenciado pela geomorfologia local.

\subsection{Depressão do Alto Paraguai}

Este compartimento geomorfológico é o mais expressivo, abrange área territorial de $418,02 \mathrm{~km}^{2}$, corresponde a 53,64 \% da bacia, encontra-se no médio curso da bacia do córrego Salobra, esta unidade corresponde a extensas áreas rebaixadas e drenadas pelos tributários do alto curso do rio Paraguai.

A rede de drenagem apresenta-se de forma meandrante divagante, influenciado pela forma do relevo. Representado no médio curso da bacia, por uma superfície de relevo pouco dissecado e rampeada. À medida que se direciona para a confluência com o rio Paraguai, o córrego Salobra perde o controle estrutural exercido pela Província Serrana, isso contribui para que o canal mude a direção de seu curso para oeste, apresentando modesto caimento topográfico.

Segundo Souza (2004), Depressão do Alto Paraguai sofreu diversos processos de erosão, que atuaram em litologias variadas estendendo-se desde o Pré-Cambriano ao Carbonífero.

A Depressão do Alto Paraguai corresponde a uma superfície de relevo pouco dissecada, com pequeno caimento topográfico de nordeste para sudoeste, interflúvios razoavelmente amplos com topos planos e drenagem pouco profunda. Apresentando-se rampeada em sua seção oeste com altimetria oscilante entre 120 e 300 metros (RADAMBRASIL,1982).

Almeida (1964), em suas descrições definiu a baixada do Alto Paraguai, como a palavra "baixada" está associada aos relevos originados por acumulação marinha, preferiu usar o termo depressão, por ser mais específico. $\mathrm{O}$ autor observou fisionomias bem distintas nas quais se individualizam pelas diferenças litológicas, organização de drenagem e pelas formas de relevo. 


\subsection{Planície do Rio Paraguai}

Após percorrer várias formações, o córrego Salobra encontra a Planície do Rio Paraguai. Este compartimento está inserido no baixo curso da bacia hidrográfica, apresenta área territorial de 36, 60 $\mathrm{km}^{2}$, corresponde a 4,63\% da bacia sendo a menor das formações geomorfológicas encontradas na bacia hidrográfica do córrego Salobra. A planície de inundação é resultante de acumulação fluvial nos ciclos de cheia do rio Paraguai. Santos (2012) enfatizam que o nível da água do rio Paraguai eleva-se durante o período de cheia, transbordando para os canais secundários, ou nas planícies marginais, provocando a remoção e a remobilização de sedimentos nesses ambientes.

A baixa declividade topográfica do rio Paraguai, mantendo apenas pequenos desníveis entre o canal principal e seu entorno, torna propícia a inundação nas planícies (SOUZA, 2004).

\section{Considerações finais}

A bacia hidrográfica do córrego Salobra constitui uma importante rede drenagem no município de Porto Estrela no Estado de Mato Grosso, Brasil, sendo contribuinte da bacia do rio Paraguai.

As estruturas geomorfológicas da bacia estão subdivididas em três unidades: Província Serrana, Depressão do Alto Paraguai e a Planície do rio Paraguai. Apresenta compartimentos geomorfológicos como superfície dissecada com serras e vales anticlinais e sinclinais; depressão e planície de inundação. A Depressão do Alto Paraguai é a formação que possui maior área de abrangência na bacia, atinge cerda de 418,02 km², correspondendo a 53,64\% seguida da Província Serrana com área aproximada de $325,17 \mathrm{~km}^{2}$, representa $41,73 \%$ da área da bacia.

\section{Referências}

ALMEIDA, F. F. M. Geologia do Centro-oeste Matogrossense. Boletim da Divisão de Geologia e Mineralogia. Rio de Janeiro, 1964.

ALMEIDA, F. F. M. Geologia da Serra da Bodoquena (Mato Grosso), B. Div. Geol. Mineral. DNPM n.219, 1965 .

ALONSO, U. R. Rebaixamento temporário de aquíferos. São Paulo: oficina de textos, 2007. 152 p.

CUNHA S. B.; GUERRA A..J.T. Geomorfologia Fluvial. In: GUERRA, A. J. T.; CUNHA, S. B. (Orgs.). Geomorfologia: uma atualização de bases e conceitos. 8 ed $^{\circ}$. Rio de Janeiro: Bertrand Brasil, 2008.

GUERRA, A.T.; MARÇAL. M. S. Geomorfologia Ambiental. Rio de Janeiro, editora Bertrand Brasil,2010.

MINISTÉRIO DO EXÉRCITO - Diretoria de Serviço Geográfico SD-21-Y-D-VI e SD-21-Y-D-III escala de 1:100. 000, 1975.

RADAMBRASIL. Levantamentos dos Recursos Naturais Ministério das Minas de Energia. Secretaria Geral. Projeto RADAMBRASIL. Folha SD 21 Cuiabá, Rio de Janeiro, 1982. 
RIBEIRO FILHO, W.; LUZ, J. S.; ABREU FILHO, W. Projeto serra Azul: reconhecimento geológico. 4 vol. Relatório final. Relatório do Arquivo Técnico (DGM, 2407). V.1. Goiânia: DNPM/CPRM, 1975.

ROSS, J. L. S. Estudo e cartografia geomorfológica da Província Serrana de Mato Grosso. Tese (Doutorado) Faculdade de Filosofia, Letras e Ciências Humanas da USP. São Paulo, 1987.

ROSS, J. L. S. Geografia do Brasil, Editora da Universidade de São Paulo, Didática, São Paulo,2011.

SANTOS, M. Uso e Ocupação da Terra e a Dinâmica Fluvial da Bacia Hidrográfica do Córrego Cachoeirinha, Município de Cáceres - Mato Grosso. 2012. Dissertação (Mestrado em Ciências Ambientais) Universidade do Estado de Mato Grosso, Cáceres.

SOUZA, I. C. Diagnóstico das condições atuais da nascente do córrego Grande afluente do rio Jauru, município de São José dos Quatro Marcos - MT. Cáceres - MT 2008.

SOUZA, C. A. Dinâmica do Corredor Fluvial do Rio Paraguai entre a cidade de Cáceres e a Estação Ecológica da Ilha de Taiamã-MT. 2004. Tese (Doutorado em Geografia) - Universidade Federal do Rio de Janeiro, Rio de Janeiro. 